\title{
Training programme for the dissemination of climatological and meteorological applications using GIS technology
}

\author{
T. De Filippis, A. Di Vecchia, G. Maracchi, and F. Sorani \\ Institute of Biometeorology - National Research Council, Florence, Italy \\ Received: 15 October 2005 - Revised: 1 March 2006 - Accepted: 5 March 2006 - Published: 6 June 2006
}

\begin{abstract}
IBIMET-CNR is involved in making different research projects and in managing operational programmes on national and international level and has acquired a relevant training competence to sustain partner countries and improve their methodological and operational skills by using innovative tools, such as Geographical Information Systems focused on the development of meteorological and climatological applications.

Training activities are mainly addressed to National Meteorological and Hydrological Services of Partner-Countries and/or to other Specialized Centers in the frame of Cooperation Programmes promoted by the Italian Ministry of Foreign Affairs mainly in favour of the Less Developing Countries (LDC) of World Meteorological Organisation (WMO) Regional Association I (Africa).

The Institute, as a branch of the WMO-Regional Meteorological Training Centre for Region VI (Europe), organizes also international training courses of high-level in Meteorology, Climatology and Remote Sensing applied to environment and agriculture fields. Moreover, considering the increasing evolution of the GIS functions for meteorological information users, IBIMET has promoted in 2005 the EU COST Action 719 Summer School on "GIS applications in meteorology and climatology". The paper offers an overview of the main institute training programmes organised to share the results of research activities and operational projects, through the exploitation of innovative technologies and tools like GIS.
\end{abstract}

\section{Introduction}

The Institute of Biometeorology of the National Research Council is focused on: applied meteorology and climatology, research activities and training programmes.

IBIMET' activities are usually carried out together with interdisciplinary projects and research on national and international level to monitor climate changes and environmental management by using simulation models and applications of remote sensing and GIS.

IBIMET has been involved, in the cooperation activities in favour of Less Development Countries (LCD) since 1986. This involvement led to the development of research and projects in the fields of agro-meteorology (Bacci et al., 1992) with special attention to food-security vulnerability mapping and Early Warning (Maracchi et al., 2003), natural resources monitoring, land recovery in arid and semiarid Regions of Africa. Various projects have been carried out under the assignment of the World Meteorological Organization (WMO), while others have been developed in collaboration with the General Direction for Development Cooperation (DGCS) of the Italian Ministry of Foreign Affairs.

IBIMET undertakes technical assistance and training activities for the National Meteorological and Technical Service of target countries and for others Local Institutions, such as the AGRHYMET ${ }^{1}$ Regional Center (Niamey-Niger) and the $\mathrm{CSE}^{2}$ (Dakar-Senegal). The topics of these activities are based on the integration of different kind of information in EWSs for decision makers support.

In particular, the main purpose of training programme is to strength the countries' capacities, to mitigate the effects of extreme events such as, drought, desertification and famine especially in arid regions of North-West and East Africa.

\footnotetext{
${ }^{1}$ AGRHYMET: Regional Training Centre for Agro- meteorology and Operational Hydrology and their Applications

${ }^{2}$ CSE: Centre de Suivi Ecologique
}

Correspondence to: T. De Filippis

(t.de.filippis@ibimet.cnr.it) 
Taking into account the Institute specific competences and the training needs of beneficiaries, the courses are usually concentrated on the following issues:

- Data Integration for Environment Monitoring;

- Data Base Management Systems;

- GIS Applications \& Remote Sensing.

Methodologies transfer, innovative tools and training activities, are the key-elements, which assure the sustainability of the international development cooperation.

IBIMET training activities are not only limited to the development of the on-going projects. On the one hand the collaboration with the Florence University led to the organization of an annual Master on Applied Meteorology, which takes place at IBIMET headquarter, while on the other hand the cooperation with the Italian National Meteorological Service made IBIMET the "operative-branch" of WMO-RMTC for RA VI.

\section{Training plans and users needs}

IBIMET experience in planning training programmes, started from the analysis of users needs of the African National Meteorological Services and Technical Organizations involved in "The Early Warning and Agricultural Production Forecast Project" (AP3A Project) and has been financed by the Italian Cooperation through WMO (WMO, 1999). The strategic purposes of this project were the development of methodologies geared toward the identification of risk zones for agricultural production in arid and semiarid region of West Africa (De Filippis et al., 2000), and the development of meteorological and climatological information products for food security and early warning at regional and national scale through the improvement of Sahelian national skills.

As a result of a decade of project activities, a stable and high quality regional geo-database has been created to improve spatial analysis, methodologies, and technical solutions. GIS products have been realized in accordance with the cultural, financial, and technical background of localinstitutions. For these reasons stand-alone GIS software and meteorological dataset, free distributed, are the training supports to enhance the application of new technologies.

The regional and national analyses of food vulnerability, in the affected areas, have been conducted on bio-physical and socio-economic data. These data have been structured into a reference personal geo-database for the nine Sahel countries and managed by the thematic cartography viewing software (VisualCarte v.1.0, 2002). The software includes a SVRP plug-in (Structural Vulnerability Representation Procedure), which allows further territorial vulnerability analysis through the creation of economic scenarios, influenced by the results of current agro-meteorological season, and represents the different kind of conditions in terms of accessibility or food availability for the target populations (VisualCarte/PRVS v.1.0, 2004).

These customized GIS tools, developed in Visual Basic ${ }^{\circledR}$ environment with the use of Library ActiveX of MapObjects2@ (ESRI), support the most common file formats in Geographic Information Systems such as ESRI shapefiles, ArcInfo coverage and grid (.adf) and Idrisi.

These applications and GIS oriented tools have been realised to satisfy the requirements of the National Technical Services for the management and analysis of spatialreference data, in order to provide decision-makers with useful information products for food emergencies management and medium and long-term development planning.

In this context, the training allowed local technicians to benefit from these innovative tools. As a matter of fact, during the last years, the increasing demand for IT training from the NMHSs, led to a re-orientation of a more "applicative" traditional didactic approach.

Training is now considered as a planned process directing learning focused on achieving specific performance objectives associated with a job (WMO, 2000), and emphasis have to be made on participants' job-competency requirements from an operational point of view.

In this framework, training is the key-element for any cooperation initiative because assures the beneficiary countries the sustainability of the programme results in the long period. At the same time, training is a great challenge because any institution involved has to find its own specific didactical approach to satisfy the participant expectations and the training needs.

A deep knowledge of the local context is necessary to meet the participant training needs, especially when you have to work with a homogeneous group of experts, coming from the same kind of institution. On the contrary if training is addressed to a heterogeneous group of experts, coming from different countries and/or types of services, the training needs can be identified with the help of potential target-user (such as NMHS' managerial team, including the chief of the training unit, or decision makers).

Last but not least, training plays an important role in the international context stability because stimulates the cooperation and communication between different countries.

\section{Didactic approach}

The definition of the didactic approach takes into consideration the training objectives based both on the participant training needs and on the course characteristics.

As we have already stressed, the main training purpose is to teach how to use the new innovative tools, like GIS, and explain the new analytical approach in order to improve national expertise and promote technical cooperation and 
information exchange between Local NMHSs and Technical Services of WMO' RA I and VI.

National and Regional spatial dataset distributed by NMHS and various organizations such as FAO, EUMETSAT, AGRHYMET or via Internet are used for tutorial exercises.

Moreover, the training purpose has not only to enrich the participants' knowledge in accordance with the specific domains, but has also to stimulate their ability to identify the information needs, necessary for the development of specific analysis.

In order to meet the "training mission," the courses are generally based on two activities: theoretical and practical. An interdisciplinary team of teachers, with alternation of classroom lectures and practical exercises, gives classes. Lectures are focused on the analysis of specific methodological approach, while exercises are based on direct application of theoretical information through the analysis of several case studies.

Therefore, training activities promote a participatory approach, giving a specific attention to the involvement of local technicians in the assessment of training needs and getting feedback from trainees during the whole process.

Training activities are based on the know-how sharing and on the evaluation of specific issues, to contribute to the adoption of an international standard language and to the valorisation of the local experiences.

\subsection{Training courses structure}

According to the framework in which training is planned, (international cooperation training programs, as RMTC or specific operational project execution, such as Ap3A), IBIMET provides different kind of training courses.

Short training courses are organized both in Florence and in partners' countries within the framework of specific programme. Training is based especially on particular GIS technical issues concerning the application of different methodological analysis approaches into operational work. The courses are addressed to technicians of National Services and are focused on specific thematic modules run by highqualified experts, with alternation of classroom lectures and practical exercises. The active participation of trainees is stimulated by discussions and exercises in working groups. It is important to stress that this kind of short courses give the possibility to meet experts coming from different countries. This heterogeneity increases the possibility of sharing different knowledge and experience and seems to be one of the most appreciate aspects of RMTC training activities, on the base of the evaluation test that is submitted to participants at the end of each course.

The brief period of this training course is not sufficient to evaluate the trainees' benefits on their future works. In order to face this lack, primary importance has to be given to the collection of didactical material. Lectures slides, papers, free software, and exercises are usually organised in a CDROM that is distributed to participants before the end of the course. In this way, they will be able to review the material and make into practice what they learned.

Long term stages generally took place during long cooperation projects. Local experts are invited to spend a period from 2 to 4 months in Florence at the premise of IBIMET to work in collaboration with Institute researchers. In this context, training is essentially on job because the trainees work on specific applications that have to be developed in the specific programme in which they are involved. The beneficiary Institution selects participants that are usually responsible for Services Technical Unit and once they are back home, they have to teach to their own experts the skills acquired during the stage.

For example: PAFAGE Project executed in cooperation with the Environment Direction of Niger, trained 3 experts responsible for the Remote Sensing, GIS and IT Units, these experts at the end of the course were be able to develop and manage the National Environmental Information System (IBIMET-CeSIA, 2004; IBIMET-CeSIA, 2005).

\section{International inter-agency training courses}

\subsection{Regional meteorological training activities - WMO}

Since 1987, WMO Executive Council decided to establish the "operative branch" of the Regional Meteorological Training Center of Region VI in Florence. As a matter of fact, the Italian National Meteorological Service could benefit of the training facilities, of ICT resources, of researcher's experience, of the scientific secretariat support of the National Research Council and of the Foundation for Applied Meteorology.

According to the decision of WMO to enlarge RMTCs training domain by including remote sensing techniques and GIS for agro-meteorological and environmental analysis applications, IBIMET courses are mainly concentrated on these issues and the attention is focused on the use of GIS potentiality for different data typology integration and analysis. Florence RMTC activities started with the development of the actions agreed with WMO regarding the Italian contribution to the famine early warning system; the common aim of RMTC and WMO is to improve the knowledge of agrometeorological methodologies and applications in $\mathrm{CILSS}^{3}$ countries affected by long lasting period of severe drought conditions at that time.

During the last tree years, RMTC increased its action field thanks to the cooperation established with EUMETSAT, UNCCD Secretariat of Convention to Combat Desertification and others European Organisation, and turned its attention to the quick development of new operational tools for environmental analysis.

\footnotetext{
${ }^{3}$ Permanent Interstates Committee for Drought Control in Sahel
} 
Nowadays the training is also addressed to the Countries with Economy in Transition of WMO RA 6 and/or RA II (Latin America) and its contents are focused on different issues, like:

- The use of Meteosat Second Generation (MSG) for the development of applications and information products;

- Maps visualization;

- Information product dissemination through customized GIS web-services.

IBIMET RMTC training advanced courses take place every year and last maximum two-weeks. The course activities are organized in a modular way (didactic sessions) and are planned for a close number of students (from 10 to 15) mainly coming from the NMHSs and/or from other scientific research institutes. Classes are given in French or English according to the speaking language of the beneficiary' countries.

The short courses, which take place in the context of a long-term programme, allow a post evaluation because you can test day by day the skills acquired by the trainees working with them on an on-going project. On the contrary, RMTC short courses do not permit this kind of post evaluation and, for this reason during the last few years, RMTC training methodology has been reviewed by IBIMET experts to give more space to practical exercises. Table 1 indicates the RMTC training courses provided since 1999.

As you can see in the Table 1, IBIMET decided to repeat the same training course on MSG applications in two different languages (French and English) in 2003 and 2004 because meteorological Community of African and European Economy in Transition expressed a great interest on MSG potentiality (WMO, 2004).

Considering MSG potentialities and training needs of MSG users, the course aims at increasing national operational capability in using mainly estimated rain data, and at supporting the current and potential meteorological satellite community.

All of this will lead to a better exploitation of the analyses and of the applications to develop in the following domains: climate monitoring, natural resources management and extreme events forecasting.

Moreover, MSG-MAP Course aims at promoting the sharing of technical capabilities and operational experience between European and African Institutions and at developing a common operational methods and techniques by using data collected by MSG.

\subsection{Mediterranean training programme}

Nowadays IBIMET-CNR is involved in proposing itself as a 'link-institution' between Mediterranean Countries following the objective of an ambitious long-term training programme that will be developed in cooperation with the
UNCCD Secretariat of Convention to Combat Desertification: Mediterranean Training Programme for the Harmonization of Early Warning Systems and Operational Instruments for Monitoring Climate Change and Desertification (MTP).

MTP aims at improving technical cooperation and information exchange among National Meteorological Services and Institutions of Mediterranean Region facilitating the building-up of a scientific network among institutions for the harmonization of methodologies and tools in climate change monitoring and desertification impact assessment.

The possibility to realize MTP Programme is founded on the convergence of various factors, such as:

- The demand for a more appropriate and effective information on national level in the countries involved in the initiative;

- The availability of new technologies for the production and dissemination of information;

- The availability of appropriate methodologies to respond requests for the improvement of quality and reliability of information.

During the next eighteen months, the three following specialized training courses will be based on meteorological and climate issues as well as on environmental monitoring for extreme events management:

1. Agro-meteorological induced disasters: prevention, monitoring, impact assessment and management;

2. Early Warning Systems for extreme events impact;

3. Desertification and environmental monitoring.

\section{Forward future developments of GIS application in meteorology and climatology}

European Cooperation in the Field of Scientific and Technical Research (COST) - is a research program within the European Science Foundation. COSTAction-719 is completely dedicated to the use of GIS in climatology and meteorology (Dyras et al., 2005). The main objective of this Action is to broaden and enhance the potential of GIS in those fields by developing applications, with emphasis on the procedures and capabilities for integrating and adding value to data from various sources and on quality control and presentation of climate and other related data (http://www.knmi.nl/samenw/ cost719/).

In this framework COST 719 Action summer school on "Application of GIS in meteorology and climatology" has been planned in September 2005 to enhance the potential of GIS applications through the improve understanding and knowledge of procedures and capabilities for integrate data from different sources. Web service technologies and Open 
Table 1. RMTC training courses.

\begin{tabular}{lll}
\hline Title & Contents & Date \\
\hline $\begin{array}{l}\text { Methodologies for remote sensing and con- } \\
\text { ventional data merging }\end{array}$ & - GIS and famine early warning systems & Florence, \\
& & $-18 / 03 / 1999$ \\
& - The Land System Analysis for the Sahelian Region \\
& - The Current System Analysis in the Sahelian Region \\
- & The application of GIS for the early warning \\
& on food security \\
- & GIS based models for operational applications: \\
& the estimation of herbaceous biomass in the Sahelian \\
& pastoral zones
\end{tabular}

Méthodologies pour l'élaboration de données agro-météorologiques et leur intégration dans les Systèmes d'Alerte Précoce pour les Régions Arides
- Meteorological data base

- Data interpolation

- Meteorological satellites

- Agrometeorological models

- Agrometeorological components of Early Warning Systems

- Tools to support EW operational applications

Planning the Response to Climatic Events and Drought Effects by Capitalizing on the Experience and Information of Operational Early Warning Systems - PRECEDE

- Climate change

- Extreme events forecast
Les Méthodologies, les Produits et les Applications à développer par l'emploi du MSG - MAP 1 Edition

Meteosat Second Generation Satellites: Applications, Products and Methodologies for Applied Meteorology and Climatology, MSG-MAP 2 Edition
Florence,

$7-18 / 05 / 2001$

Florence,

7-18/10/ 2002

- Integration of multi-source data for analysis and planning

- Operational Early Warning Systems

- New technologies for information dissemination

- Introduction to MSG System

Florence,

3-14/11/ 2003

- Meteorological Products

- Climate modelling and seasonal forecast

Florence, $15-26 / 11 / 2004$

- Agro-meteorological applications

- GIS application for meteorological data integration and analysis
Source solutions have been introduced in this advanced training course. The course specific objective was to facilitate the building-up of a scientific network among European Institutions for the harmonization of GIS methodologies and tools used in promoting the development of applications for climate and meteorological analysis.

Last but not least, the course aims at establishing common and integrated approach, operational methods, and techniques using GIS applications.
Training has been focused on the following main topics treated in different thematic sessions:

- Data models in GIS and Atmospheric Science: integration and interoperability;

- Spatial interpolation methods in GIS;

- Application of GIS in meteorology and climatology for natural resource management; 


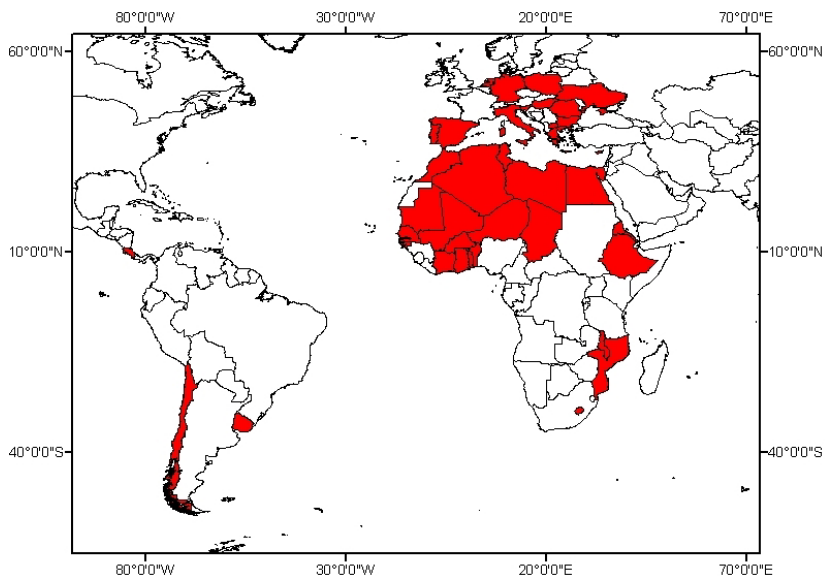

Fig. 1. Countries covered by IBIMET training courses.

Each session includes lectures, group exercises and discussions. The course is based on active student participation, and trainees have been invited to present in class their experience on selected topics. A central component of the course is the presentation of case studies organized around some COST 719 key issues with papers presented by the chairperson or invited speakers.

Active participation of students has been encouraged in order to stimulate the establishment of a structured interregional exchange of scientific and technical expertise.

\section{Conclusions}

Training courses was designed and planned to assure the transfer of the results achieved by international cooperation project in order to:

- transfer of know how from research to operational applications;

- enhance the use of multi source integrated analysis approach developed in GIS environment;

- disseminate information more comprehensible by decision-makers;

- increase the capacity building of Institutions involved in the national and regional famine Early Warning systems;

- support the Local Technical Services (NHMS, EWS, etc.);

- promote data and information dissemination by web;

- develop of customized GIS tools and functions to ensure to all potential users the access by a user-friendly interface to the entire cartographic information for deeper meteorological and climatological applications.
More than 120 people from NMHSs and EWS of nine countries of Sahels Region have been trained on use of geographic products and their related tools to provide useful information for an early warning in food security system and for the monitoring of emergency situations.

The results are tangible looking the cartographic representation of products published on national and regional meteorological bulletins (AGRHYMET, 1996-2005) and web pages.

The RMTC activities, that have touched more than 60 technical officers of National Services of 30 countries, as show in (Fig. 1) allow to continue to educational grow of new job-profiles that the rapid evolution of ICT requires.

The future looks to assess existing atmospheric data formats and identify mechanisms for data conversion in order to make formats more compatible with GIS systems and encourage inter-disciplinary interactions for meteorological and climatological applications.

Acknowledgements. The authors thank all the following Institutions for the scientific contribution to training activities and fellowship grant support;

- World Meteorological Organization - WMO

- European Organization for the Exploitation of Meteorological Satellites - EUMETSAT

- Secretariat of the United Nations Convention to Combat Desertification - UNCCD Secretariat

- Italian Ministry of Foreign Affaires

- Foundation for Applied Meteorology

- EU COST Action 719

Edited by: E. Cutrim, M. Ramamurthy, S. Nativi, and L. Miller Reviewed by: anonymous referees

\section{References}

AGRHYMET: Monthly Bulletins, 1996-2005.

Bacci, L., Maracchi, G., Senni, B.: Les stratégies agrométéorologiques pour les pays Sahéliens, IATA-CeSIA (Ed.), pp. $175,1992$.

De Filippis, T., Djaby, B., Di Vecchia, A., and Tarchiani, V.: Identification of risk zones for rain crop production in Sahelian countries using METEOSAT images, Proceedings of "The 2000 EUMETSAT Meteorological Satellite Data User' Conference”, Bologna, Italy, 29 May-2 June, 489-496, 2000.

Dyras, I., Dobesch, H., Gruter, E., Perdigao, A., Tveito, O. E., Thornes, J .E., Van der Wel, F., and Bottai, L.: The use of Geographic Information Systems in climatology and meteorology: COST 719, Meteorol. Appl., Cambridge University Press, Cambridge, UK, 12(1), 1-5, 2005.

IBIMET-CeSIA and DSCF/DE (Ed.): Le Système d'Information sur les Forêts Classées du Niger, ISBN 88-87401-04-7, 2004.

IBIMET-CeSIA and DSCF/DE (Ed.): Le Système d'Information Environnementale de Keita, ISBN 88-87401-05-5, 2005. 
Maracchi, G. and Pini, G.: The Ibimet-CNR approach to early warning for food security analysis, Proceedings of an International Workshop "Crop and rangeland monitoring in eastern Africa for early warning and food security" organised by FAO and JRC, Nairobi, Kenia, 28-30 January, ISBN 92-894-6521, 139-145, 2003.

VisualCarte 1.0: Système de Gestion de la Cartographie Thématique, IBIMET-CNR (Ed.), ISBN 88-900502-8-4, 2002.
VisualCarte/PRVS 1.0: Procédures de Représentation de la Vulnérabilité Structurelle, IBIMET-CNR (Ed.), ISBN 88900502-8-4, 2004.

WMO: WMO Bulletin, 48(4), 488-491, 1999.

WMO: Guidelines for the Education and Training of Personnel in Meteorology and Operational Hydrology, WMO-No.258, Vol. I - Meteorology, 2000.

WMO: WMO Bulletin (October), 355-356, 2004. 